\title{
GROWTH AND DEVELOPMENT IN A GROUP OF CHILDREN OF VERY LOW BIRTH WEIGHT
}

\author{
BY \\ CECIL M. DRILLIEN \\ From the Department of Child Life and Health, University of Edinburgh
}

(RECEIVED FOR PUBLICATION JULY 22, 1957)

In recent years improved techniques in premature baby care have resulted in a greatly improved expectation of life for the very small, premature baby. Table 1 gives the survival rates from one

TABLE 1

SURVIVAL RATES FOR BABIES OF $5 \frac{1}{2}$ LB. AND UNDER AT BIRTH IN ONE EDINBURGH MATERNITY HOSPITAL

\begin{tabular}{cc|r|r}
\hline & \multicolumn{2}{|c}{ Percentage Survival } \\
\cline { 3 - 4 } Weight in lb. & 1945 & 1954 \\
\hline 5 to $5 \frac{1}{2}$ & $\cdots$ & $91 \cdot 6$ & $96 \cdot 3$ \\
$4 \frac{1}{2}$ to 5 & $\cdots$ & $83 \cdot 3$ & $84 \cdot 6$ \\
4 to $4 \frac{1}{2}$ & $\cdots$ & $81 \cdot 6$ & $82 \cdot 4$ \\
$3 \frac{1}{2}$ to 4 & $51 \cdot 8$ & $71 \cdot 4$ \\
3 to $3 \frac{1}{2}$ & $\cdots$ & $35 \cdot 0$ & $73 \cdot 0$ \\
Under 3 &. & $4 \cdot 5$ & $28 \cdot 2$ \\
\hline
\end{tabular}

large Edinburgh maternity hospital for six premature weight groups in the years 1945 and 1954. It will be seen that the most striking improvement is found in the lowest weight groups. This raises the important question of what happens to these very small babies in later life. Although there is an extensive literature on the growth and development of premature babies, the majority of investigators have considered premature babies as a whole, i.e., all those with a birth weight of $5 \frac{1}{2} \mathrm{lb}$. $(2,500 \mathrm{~g}$.) or less, the samples studied being heavily weighted by the larger premature infants. A recent survey of all premature births in Edinburgh, in the years 1952 to 1953 (Drillien and Richmond, 1956), showed that $57 \%$ of all births registered as being premature by weight were between $4 \mathrm{lb} .9 \mathrm{oz}$. and $5 \mathrm{lb} .8 \mathrm{oz}$. at birth. In another investigation (Drillien, 1957), it was shown that amongst primiparae $49 \%$ of babies considered premature on a weight basis were reported as having a gestation time of 38 weeks or longer; the comparable figure amongst higher parities was $37 \%$. The majority of these small, full-time babies weighed between 5 and $5 \frac{1}{2} \mathrm{lb}$. at birth, and practically all of them were over $4 \frac{1}{2} \mathrm{lb}$. $(2,041$ g.).
It appears, therefore, that the effect of prematurity on later growth and development may be seriously underestimated if the sample studied contains an undue proportion of small but mature infants.

Hess and Lundeen (1949) in their book, "The Premature Infant', describe briefly a follow-up investigation of 259 infants born between 1922 and 1947 whose birth weights varied from 735 to $1,260 \mathrm{~g}$. (1 lb. $10 \mathrm{oz}$. to $2 \mathrm{lb} .8 \mathrm{oz}$.). Two hundred and twelve $(82 \%)$ were traced and examined. These cases were graded as to physical and mental development: $48 \%$ were considered to be of average physical development and $59 \%$ of average mental development. Unfortunately no details are given of the criteria of normality used.

Howard and Worrell (1952) quote a personal communication from Hess regarding the progress of 317 children who were then 8 years or older, of birth weight between 605 and 1,260 g. (1 lb. $5 \mathrm{oz}$. to $2 \mathrm{lb} .8 \mathrm{oz}$.). Of these, $51 \%$ were considered to be of normal physical status and $64 \%$ of average mental development, figures closely paralleled by the previous investigation.

Kunstadter and Bartelme (1934) describe in detail the findings in 17 children surviving a birth weight of less than $1,000 \mathrm{~g}$. (2 lb. $3 \mathrm{oz}$.). Of these, five died after discharge from hospital and before the age of 2 years. Developmental testing was carried out on 10 of the children: five were considered to be of normal or superior intelligence, and five definitely retarded. Out of eight cases, in which reports were given as to emotional stability, four were regarded as having marked behaviour problems, two as having minor behaviour problems and two were said to be stable and emotionally mature. Nine children over the age of 1 year were weighed and measured: eight were found to be underweight, most of them considerably so. These eight children were also retarded in height, but not to the same extent as in weight.

Knobloch, Rider, Harper and Pasamanick (1956) describe the findings in 57 infants at 9 months of 
age, whose birth weight was $1,500 \mathrm{~g}$. ( $3 \mathrm{lb} .4 \mathrm{oz}$.) or less, this being a part of a wider study of premature infants of different birth weights. They considered that in this low birth weight group $44 \%$ of the infants had an abnormal condition of sufficient magnitude to cause serious concern about the prognosis for future development. The comparable incidence for the rest of the premature infants was $8 \cdot 6 \%$ and for full-term infants $2 \cdot 6 \%$.

\section{Method of Investigation}

A long-term study of the growth and development of premature and mature infants, born in Edinburgh hospitals between the years 1953 and 1955, yielded 20 children whose weight was $3 \mathrm{lb}$. or less at birth. In view of the small number it was decided to continue to follow up all cases in this low birth weight group born after 1955, and also to go back over a period of years in order to collect a larger number of these children. In all a total of 75 names was obtained. In every case the family has been traced, and in all but one where the family had

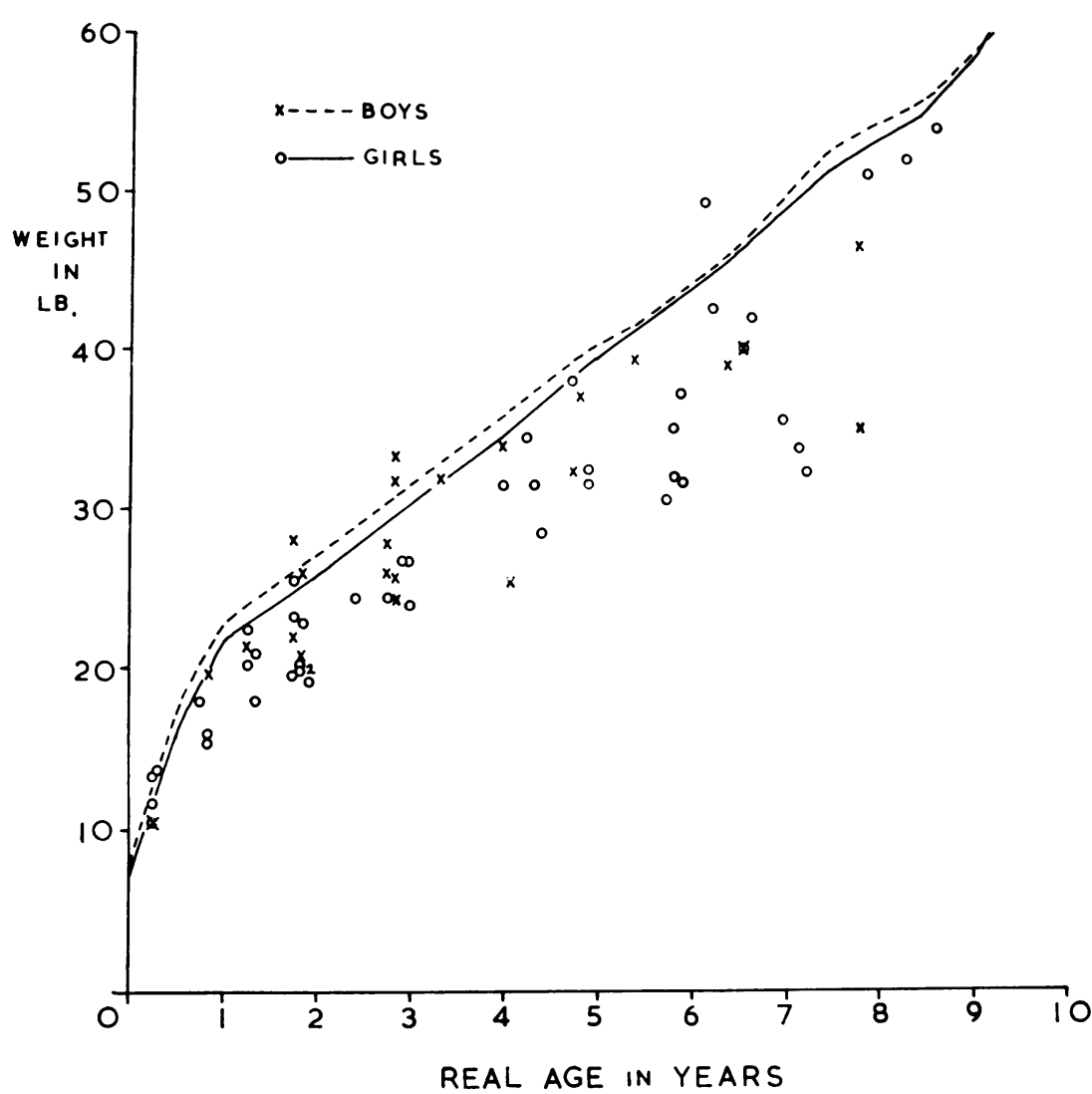

FIG. 1.- Weights of prematurely born children compared with mean weights of normal children. moved out of the district, the mother has been interviewed and living children examined.

Table 2 gives the numbers of children by age of

TABLE 2

COMPOSITION OF THE SAMPLE

\begin{tabular}{|c|c|c|c|c|}
\hline Age & & Total & Boys & Girls \\
\hline $\begin{array}{l}6 \text { months } \\
1 \text { year } \\
1 \frac{1}{2} \text { years } \\
2 \text { years } \\
2 \frac{1}{2} \text { years } \\
34 \text { years } \\
4 \text { to } 5 \text { years } \\
5 \text { to } 6 \text { years } \\
6 \text { to } 7 \text { years } \\
7 \text { to } 8 \text { years } \\
8 \text { to } 9 \text { years }\end{array}$ & \begin{tabular}{l|}
$\cdots$ \\
$\cdots$ \\
$\cdots$ \\
$\cdots$ \\
$\cdots$ \\
$\cdots$ \\
$\cdots$ \\
$\cdots$ \\
$\cdots$
\end{tabular} & $\begin{array}{r}5 \\
4 \\
5 \\
12 \\
1 \\
10 \\
12 \\
5 \\
7 \\
3 \\
5\end{array}$ & $\begin{array}{l}1 \\
1 \\
1 \\
4 \\
-6 \\
6 \\
5 \\
1 \\
2 \\
2\end{array}$ & $\begin{array}{l}4 \\
3 \\
4 \\
8 \\
1 \\
4 \\
7 \\
4 \\
5 \\
3 \\
3\end{array}$ \\
\hline Total & .. & 69 & 23 & 46 \\
\hline
\end{tabular}

the last examination. It will be noticed that there are nearly twice as many girls as boys in this sample, due no doubt to their slightly longer gestation time for any given birth weight, associated with the fact that girls withstand the hazards of birth better than boys of like weight. All cases of 3 years and under are included in the larger survey and are seen at regular six-monthly intervals. Over this age the children have been seen on one or two occasions only. Five children died before the age of 2 years.

In one case the child died at 18 months, the cause of death being bronchopneumonia. In the other four cases, in which death occurred at 6 months or earlier, the cause of death was not known. In two cases the child was found dead in the cot, having been apparently quite well a few hours earlier. In the other two cases, the child appeared fretful and refused feeds in the evening and died the following morning before medical aid was summoned.

\section{Physical Development}

The children were weighed in light, indoor clothes without shoes, 
and an appropriate deduction was made for the amount of clothing still worn. All children of 2 years and over were measured recumbent, without shoes, on a portable measuring board.

Normal weight and length curves were constructed from means for Edinburgh infants, pre-school and school children (1951 to 1956) given in 'Disease in Infancy and Childhood' Ellis (1956).

In the accompanying figures the weeks of prematurity have been deducted from the chronological age to give the real age.

Fig. 1 gives the weights of 69 children, 46 girls and 23 boys, at the time of their last examination. Except in the first six months of life almost all are underweight, many considerably so, even when allowance is made for the degree of prematurity.

Fig. 2 shows the lengths of 54 children, 35 girls and 19 boys. The retardation in length is not so marked as for weight. This is demonstrated in Fig. 3, where curves have been constructed from the figures used previously for normal weight and length, giving the expected ratio of weight to

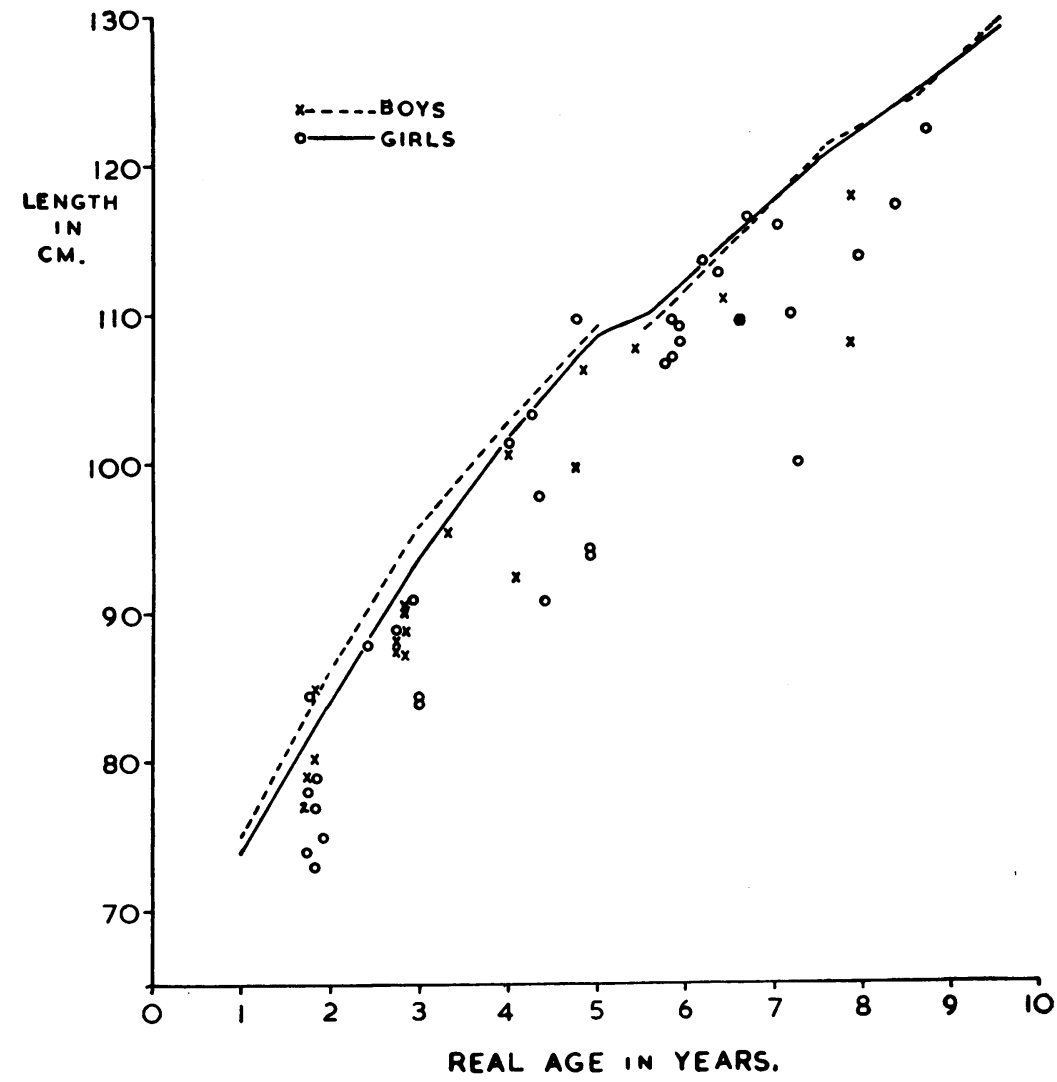

FIG. 2.-Lengths of prematurely born children compared with mean lengths of normal children.

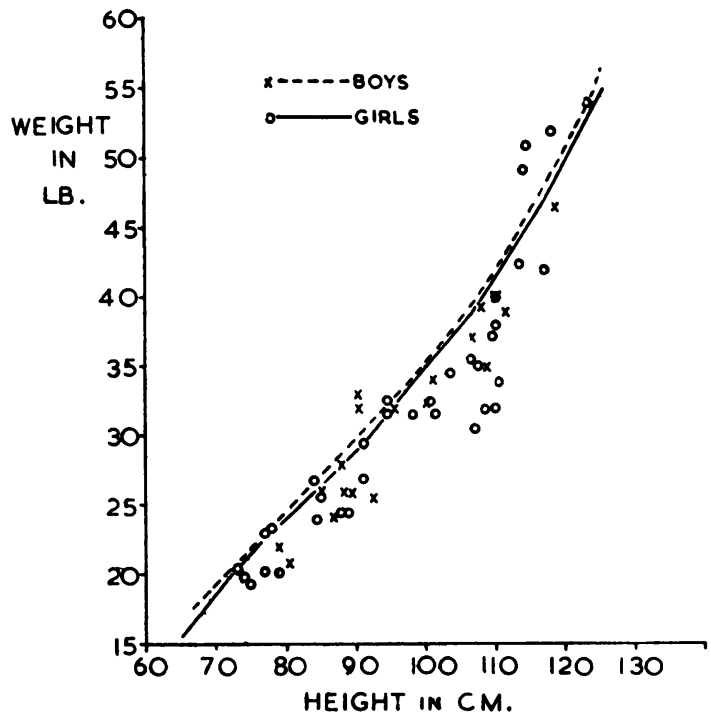

Fig. 3.-Height/weight ratios in prematurely born children compared with those for normal children.

length. It will be seen that many of the premature children are markedly underweight for their height, as well as being generally small for their age.

Figs. 4 and 5 present the same data in a different way. For every case, excepting those of 6 months and younger, the ratio is given, expressed as a percentage, of the 'weight age' to the real age of the child, the 'weight age' being the age at which a 'normal' child would have the weight of the child in question. For children of 2 years and over, a similar ratio has been calculated of 'length age' to real age. Again allowance has been made for degree of prematurity. The data are summarized in Table 3. The figures show that there is no apparent tendency for physique to improve with age, the proportion of undersized children remaining steady throughout the age period under review. 


\section{Mental Development}

All children of 3 years and under were given developmental tests based on those described by Gesell (1941, 1950). It was not possible to carry out the complete battery of tests in every case, but in the majority information has been obtained as to ability in locomotor activities, hand manipulation, language and social adjustment. These cases are included in the larger survey and have been tested at regular six-monthly intervals. For each case the developmental quotient (D.Q.) has been calculated.

The D.Q. is the relationship between 'maturity age' and actual age, expressed as a percentage value.

D.Q. $=$ Chronological age - weeks of prematurity $\times 100$

Children over the age of 3 years were tested on the Terman Merrill L. test. In those cases where the child was markedly retarded, Gesell tests were used up to the 3-year level, and Terman Merrill tests also used if the child showed an average result, at the 3-year level, on the Gesell tests.

In assessing the mental development of the school

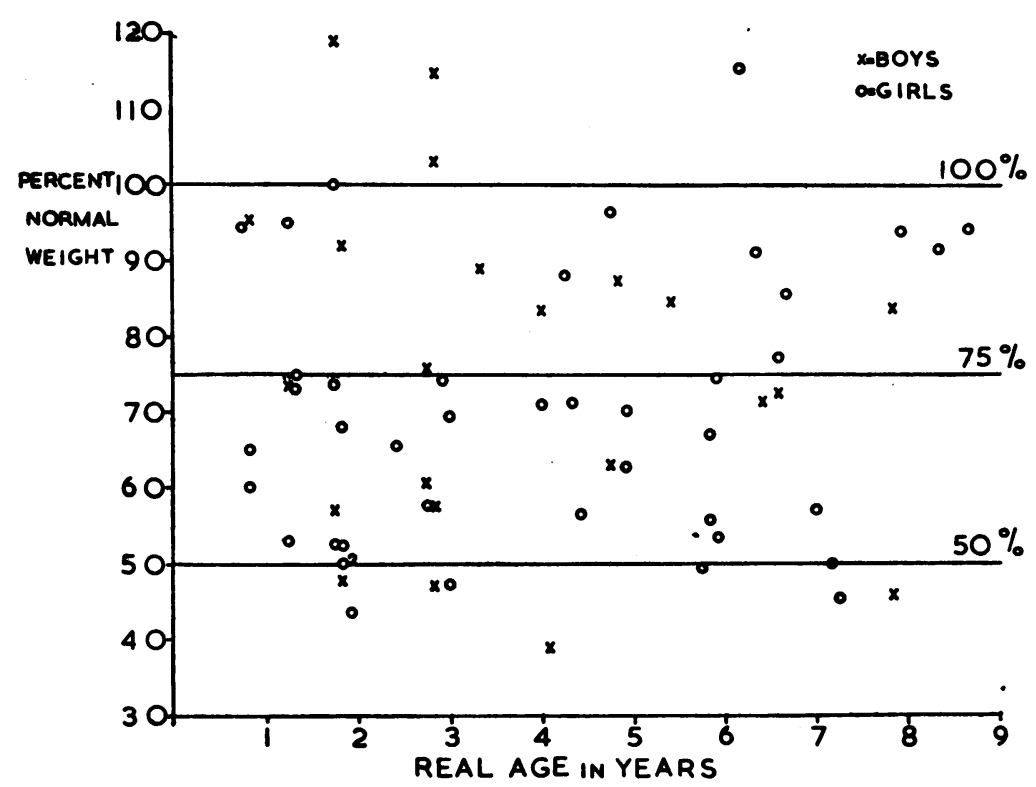

FIG. 4.-Ratios of 'weight age' to real age in prematurely born children. 


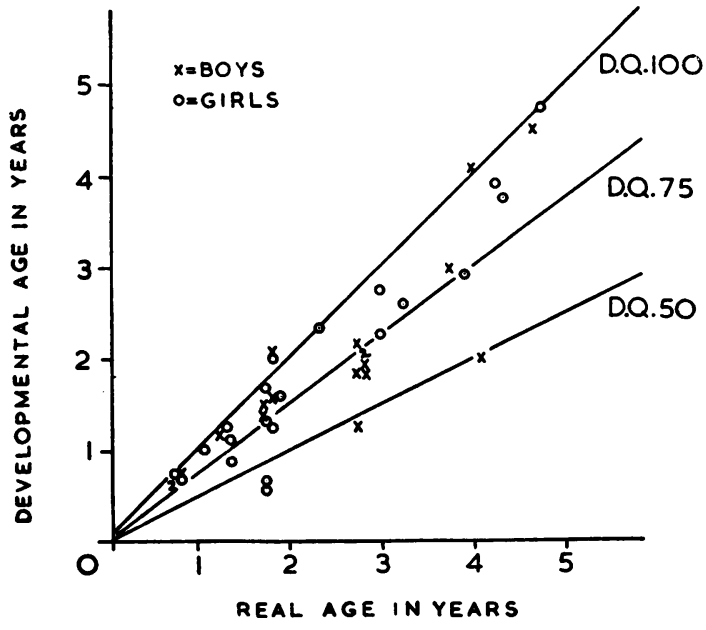

Fig. 6.-Developmental quotients for 38 pre-school prematurely born children.

can be considered normal, or superior in mental ability. Thirteen children $(34 \%)$ have a D.Q. between 75 and 89 , and are definitely dull; seven $(18 \%)$ between 50 and 74 may be considered highgrade defectives; and four $(11 \%)$ below 50 as grossly defective.

The children of 3 years and under, who are included in the larger survey, have been compared with other children in the survey of different birth weights. In each case the child included in this study has been matched with others of like age and sex selected at random from the main survey. Allowance has been made for the degree of prematurity in each of the three premature groups. Table 4 gives the average D.Q. for
PERCENT
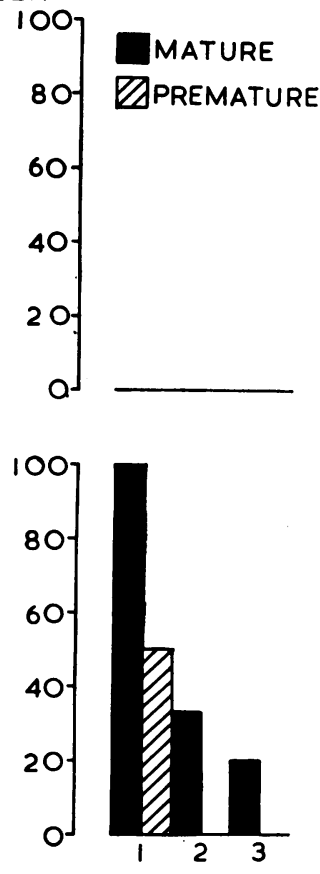

12 MONTHS children in four birth weight groups, the difference in D.Q. compared with children mature at birth, and tests of significance for this difference. It will be seen that the average D.Q. rises steadily with increasing birth weight, and in each case the difference is significant. However, it is only in the smallest weight group

TABLE 4

AVERAGE D.Q. LEVELS IN PREMATURE AND MATURE CHILDREN

\begin{tabular}{c|c|c|c|c}
\hline & \multicolumn{3}{|c|}{ Birth Weight (lb. oz.) } & \\
\cline { 2 - 5 } & $\begin{array}{c}5.9 \text { and } \\
\text { Over }\end{array}$ & 4.9 to $5 \cdot 8$ & $3 \cdot 1$ to 4.8 & $\begin{array}{c}\text { 3 and } \\
\text { Under }\end{array}$ \\
\hline $\begin{array}{c}\text { Average D.Q. } \\
\text { Difference from } \\
\text { mature group } \\
t\end{array}$ & 106 & 99 & 95 & 81 \\
$p$ & & 7 & 11 & 2.5 \\
$p$ & & 2.36 & 2.98 & 7.84 \\
& 0.025 & 0.01 & 0.001 \\
\hline
\end{tabular}

that a substantial difference in D.Q. is found. The prematurely born children, as a whole, tend to come from an inferior socio-economic level than those in the mature group, and there is no doubt that the intelligence of the parents in the latter group tends to be higher and the home environment more favourable. This, by itself, may account for the
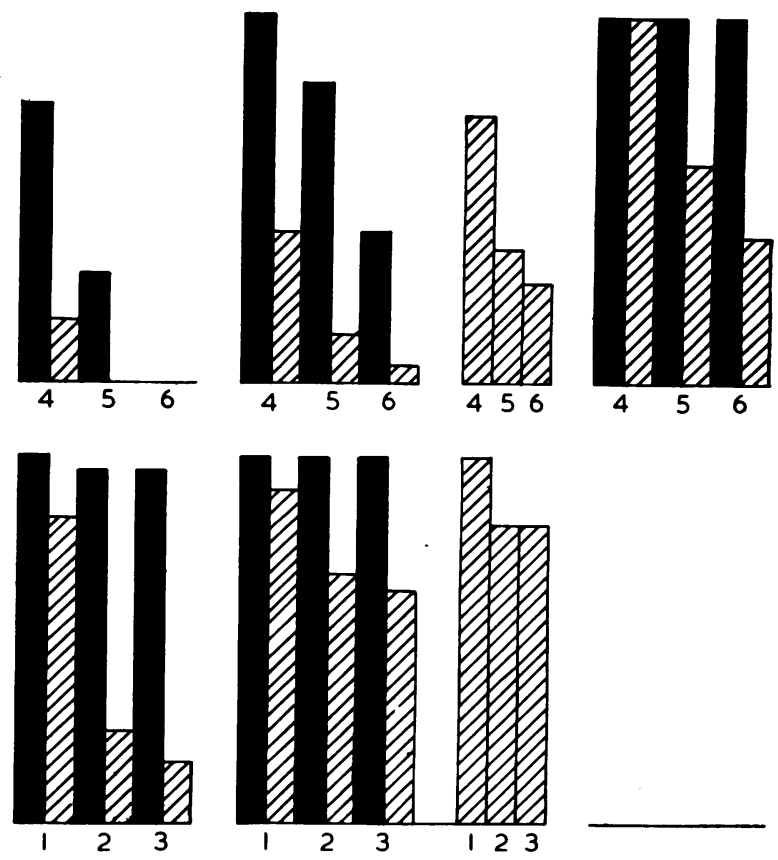

18 MONTHS

24 MONTHS 3OMTHS. 36 MONTHS

FIG. 7.-Milestones of development in premature and mature children: (1) sitting, (2) standing, (3) walking, (4) single words, (5) phrases, (6) sentences. 
small differences found in D.Q. level between the larger premature children and the mature children. However, in the smallest weight group the difference is so great that it seems probable that the low D.Q. scores are directly connected with the low birth weight.

The ages at which certain milestones were passed in locomotion and speech development in the first three years have been compared in those who were $3 \mathrm{lb}$. or under at birth and those over $5 \frac{1}{2} \mathrm{lb}$. and the results are shown in Fig. 7.

The lower section of the figure shows the number of children, expressed as a percentage, at any given age who were able to (1) sit unsupported for 10 minutes or longer; (2) stand unsupported for 30 seconds or longer; (3) walk alone across a room.

The upper section shows the percentage who (4) had five or six definite words, apart from Mamma and Dadda; (5) had many single words and several two- or three-word phrases; (6) were speaking in broken sentences.

The maturely born children were not examined at 30 months. It will be seen that for locomotor activities the premature group had nearly reached the 18-month mature level by the age of 30 months, and, in speech, at 3 years they were still rather behind the mature 2-year-old level.

It is not possible to say at this stage whether there is likely to be any substantial improvement as the children get older. Out of 21 children under 3 years of age seen at regular intervals, 13 have remained at approximately the same D.Q. level (a change up or down of 8 points or less), six have definitely improved and two have deteriorated.

An attempt has been made to correlate conditions at birth and during the first few weeks of life with later mental development. In 59 cases, full records were available. In 15 cases, the baby's condition at birth was very poor, respiration was established with difficulty and cyanotic or cerebral attacks occurred during the next two weeks. Ten of these babies later showed definite mental retardation. In 36 cases, the babies caused little anxiety either at the birth or during their stay in hospital. Of these, 15 later appeared to be definitely retarded. In general one may say that it appears very difficult to judge from immediate post-natal findings what the ultimate prognosis will be.

\section{Mental Development in School Age Children}

Five school age children are attending the Royal Blind School, Edinburgh. In supplying an estimate of intelligence, the Headmaster stressed the difficulty of obtaining accurate I.Q. scores in the presence of emotional difficulties.

\begin{tabular}{|c|c|c|}
\hline \multicolumn{2}{|c|}{ Age } & \multirow{2}{*}{ I.Q. } \\
\hline Yr. & Mth. & \\
\hline $\begin{array}{l}5 \\
6 \\
6 \\
6 \\
6\end{array}$ & $\begin{array}{r}10 \\
2 \\
11 \\
2 \\
9\end{array}$ & $\begin{array}{l}80 \text { approximately } \\
80 \text { to } 95 \\
80 \text { approximately } \\
\text { Testing impossible owing to considerable degree } \\
\text { of emotional disturbance, but both appear } \\
\text { retarded }\end{array}$ \\
\hline
\end{tabular}

Thirteen children attending the ordinary primary schools were given intelligence tests. Terman and Merrill $L$ or $M$ scale tests were used except in the case of one Polish boy with a poor grasp of the English language, who was also given the Wechsler intelligence scale for children.

The estimated I.Q.s of these children and assessments of educational attainments are as follows:

\begin{tabular}{|c|c|c|c|}
\hline \multicolumn{2}{|c|}{ Age } & \multirow[b]{2}{*}{ I.Q. } & \multirow[b]{2}{*}{ Educational Attainment } \\
\hline Yr. & Mth. & & \\
\hline $\begin{array}{l}5 \\
6 \\
6\end{array}$ & $\begin{array}{l}5 \\
1 \\
5\end{array}$ & $\begin{array}{r}109 \\
77 \\
84\end{array}$ & $\begin{array}{l}\text { Satisfactory start with formal work } \\
\text { Not ready for formal work } \\
\text { Below average, especially in number }\end{array}$ \\
\hline 6 & 6 & 87 & $\begin{array}{l}\text { Below average, especially in number } \\
\text { work. To be kept back one } \\
\text { year. Twin ( } 3 \mathrm{lb} \text {. } 6 \mathrm{oz} \text {.) is in } \\
\text { class for age }\end{array}$ \\
\hline 6 & 10 & $\begin{array}{c}\text { Wechsler } \\
\text { Verbal } 81 \\
\text { Performance } 101\end{array}$ & $\begin{array}{l}\text { Successfully overcoming handicaps } \\
\text { of poor health (spastic) and }\end{array}$ \\
\hline 6 & 11 & 82 & $\begin{array}{l}\text { Severely retarded but has defective } \\
\text { vision and hearing }\end{array}$ \\
\hline $\begin{array}{l}7 \\
7\end{array}$ & $\begin{array}{l}4 \\
6\end{array}$ & $\begin{array}{l}89 \\
80\end{array}$ & $\begin{array}{l}\text { In class for age } \\
\text { Severely retarded. Has been kept } \\
\text { back one year }\end{array}$ \\
\hline $\begin{array}{l}8 \\
8 \\
8\end{array}$ & $\begin{array}{l}3 \\
3 \\
3\end{array}$ & $\begin{array}{l}91 \\
83 \\
85\end{array}$ & $\begin{array}{l}\text { Is in class for age } \\
\text { Is in class for age } \\
\text { Severely retarded especially in } \\
\text { number work. Has been kept }\end{array}$ \\
\hline 9 & 2 & 84 & Is in class for age \\
\hline
\end{tabular}

Three children have not been given intelligence tests. Class teachers' reports are given below:

\begin{tabular}{|c|c|c|}
\hline \multicolumn{2}{|c|}{ Age } & \multirow[b]{2}{*}{ Educational Attainment } \\
\hline Yr. & Mth. & \\
\hline $\begin{array}{l}6 \\
7 \\
8\end{array}$ & $\begin{array}{l}4 \\
0 \\
8\end{array}$ & $\begin{array}{l}\text { Below average but making progress } \\
\text { Below average. Has been kept back one year. } \\
\text { Twin ( } 3 \mathrm{lb} \text {. } 7 \text { oz.) is in class for age } \\
\text { Below average in all subjects }\end{array}$ \\
\hline
\end{tabular}

Of a total of 21 children, therefore, only three are considered to be of average intelligence and the majority are very dull. However, they all entered school at the usual age and at present are considered to be of sufficient intelligence to benefit from normal primary schooling. In the pre-school group of 38 children, at least seven appear to be so grossly retarded that it seems unlikely that they will be able to begin school at 5 years, or attend normal school.

In general the school age children appear to show 
less mental damage than those born in the past three years. This may be due to the fact that there is steady improvement with increasing age, but it seems more likely that with improved techniques in premature baby care damaged children are now surviving who would not have done so some years ago. This supposition is strengthened by the fact that of a total of six children with cerebral diplegia, only one is of school age, the other five being 3 years old or younger.

\section{Illness in Early Life}

The amount of illness suffered in the early years of life by the very small premature babies has been compared with that reported during the same age period for an equal number of mature babies of like sex and age.

Table 5 gives the number of children in each

TABLE 5

MORBIDITY IN FIRST THREE YEARS IN PREMATURE AND MATURE CHILDREN

\begin{tabular}{|c|c|c|c|c|c|}
\hline \multirow[b]{2}{*}{ Age } & \multirow[b]{2}{*}{ No. } & \multicolumn{2}{|c|}{ No Illnesses } & \multicolumn{2}{|c|}{ Percentage } \\
\hline & & $\begin{array}{c}\text { Prema- } \\
\text { ture }\end{array}$ & Mature & $\begin{array}{c}\text { Prema- } \\
\text { ture }\end{array}$ & Mature \\
\hline $\begin{array}{l}\text { Birth to } 6 \text { months } \\
6 \text { to } 12 \text { months } . \\
12 \text { to } 18 \text { months .. } \\
18 \text { to } 24 \text { months . } \\
24 \text { to } 36 \text { months .. }\end{array}$ & $\begin{array}{r}36 \\
31 \\
20 \\
20 \\
9\end{array}$ & $\begin{array}{r}20 \\
12 \\
14 \\
11 \\
3\end{array}$ & $\begin{array}{r}29 \\
24 \\
16 \\
16 \\
3\end{array}$ & $\begin{array}{l}56 \\
39 \\
54 \\
55 \\
33\end{array}$ & $\begin{array}{l}81 \\
78 \\
62 \\
80 \\
33\end{array}$ \\
\hline
\end{tabular}

group who were reported as having had no illnesses, apart from head colds and minor digestive disturbances, during the previous six months. Eleven hospital admissions, for medical illness, were reported, 10 of them in the premature group. In each case, except one where the baby was admitted to hospital for failure to thrive, the diagnosis was bronchitis or pneumonia. The premature babies appeared to be particularly susceptible to lower respiratory infections. Twenty-four episodes of bronchitis or pneumonia were reported in this group compared with seven in the mature group. Frequent chesty colds during the previous six months (the mother stating that 'the doctor is never away from the door') were reported on 24 occasions in the premature group compared with six in the mature group. The figures for other illnesses are approximately equal in the two groups, except for specific infections which were more common amongst mature babies, particularly between 2 and 3 years, no doubt due to the fact that fewer of these children were firstborn, and also that in general they were allowed out to play and mixed with other children at an earlier age.

In the premature group there were two cases of spastic diplegia, one of spastic paraplegia and two of spastic hemiplegia. One child had a considerable degree of deafness, and one suffered from epilepsy. Out of a total of 12 boys, three had unilateral or bilateral inguinal hernia.

Out of a total of 29 children between the ages of 3 and 9 years, about whom a reliable history could be obtained, 12 were reported as having had frequent chesty colds, bronchitis and pneumonia. One boy, aged 5 years, improved as he grew older, but in the other 11 cases the predisposition to lower respiratory infections had persisted since infancy. One school age boy suffered from spastic diplegia.

\section{Visual Defects}

A high proportion of the very small, premature babies were later found to have a visual defect. Out of 43 children between the ages of $2 \frac{1}{2}$ years and 9 years, $21(49 \%)$ were found to have some visual defect, as shown in Table 6 . Twenty of the total

TABLE 6

VISUAL DEFECTS IN 43 CHILDREN AGED $2 \frac{1}{2}$ TO 9 YEARS

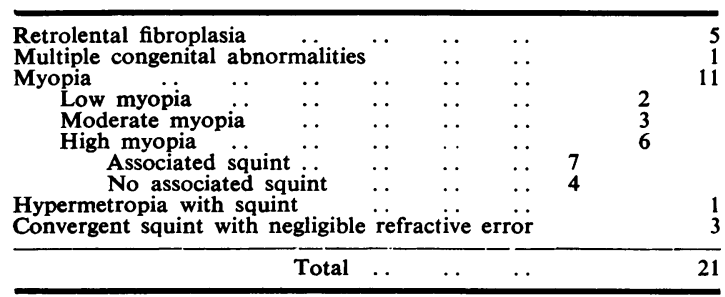

were of school age and all of them had been seen by the school ophthalmologist. Twenty-three were under school age and had not been seen by an ophthalmologist, except in cases of obvious defect. In the school age group, 13 were found to have some abnormality, i.e., $65 \%$. In the pre-school group, $35 \%$ had an obvious defect. It therefore seems probable that some of the pre-school children may be found to have some minor defect of vision when they go up for routine examination on entry into school.

The commonest disorder found was myopia of varying degree. Eleven children were found with this condition, six of them with a considerable degree involving fundal changes. Five children had retrolental fibroplasia with very little useful vision. Of the school age group, five were attending the Royal Blind School.

\section{Emotional Disorders}

All the mothers were questioned as to the behaviour of the child: how he reacted to other 
children and adults, whether there had been any particular problems associated with toilet training, sleeping or feeding habits, and in particular whether the child had been more difficult to handle than his siblings.

Children under the age of 3 years are not included in these results as minor behaviour problems are so common between the ages of 18 months and 3 years as to be considered a part of normal development.

Out of a total of 42 children between the ages of 3 and 9 years, 14 mothers stated that the child had been easy to handle and that there had not been any but minor problems of behaviour. In 28 cases $(66.7 \%)$, there were, or had been, problems of sufficient degree to be considered abnormal in the particular age group concerned. In 14 cases $(33.3 \%)$, the emotional disorders could be considered of quite a severe degree. In 17 cases, the child was described as being excessively timid and shy and very dependent on the mother. Characteristically the mother would state that the child was reluctant to go out to play, could never be left with a neighbour, refused to attend Sunday school with older brothers and sisters, and, in the case of schoolage children, took a long time to settle down at school. One boy, who lived close to his school, ran away home at play time every day during his first two years at school. Developmental testing with these children was very difficult, cooperation was poor, the child clinging to mother and crying, or remaining obstinately silent. Physical examination and measuring were often resisted vigorously.

Eleven children were described as being highly strung, excitable and nervous, with many fears. Toilet problems and persistent bedwetting after the age of 5 years were reported in six cases. One boy, who attended the ordinary public school, was totally incontinent until the age of 7 . Nine children were said to indulge in wild temper tantrums. Head banging, induced vomiting and breath holding were reported in the 3-5 age-group. Two school-age children would throw themselves on the floor, kicking and screaming when thwarted. Sleeping problems and night terrors were described in six cases. One boy of 6 years wakes nearly every night screaming and has to be taken into the parents' bed. This had been going on for several years.

The Headmaster of the Royal Blind School stated that the cases of retrolental fibroplasia attending the school were generally more difficult to handle, and less mature emotionally than other blind children of normal birth weight.

Thirty of the children examined had older or younger siblings. In 11 cases the mother stated that the premature baby had been no more difficult to handle than her other children. In 19 cases $(63 \%)$ the child has always been more difficult than siblings of normal birth weight.

In four cases the child was one of twins, the other child being over $3 \mathrm{lb}$. at birth.

Case 1. These twins are aged 7 (twin I, birth weight, 2 lb. 14 oz., twin II, birth weight, $3 \mathrm{lb}$. $7 \mathrm{oz}$.), and both children have always been easy to handle. Neither has exhibited any marked behaviour problems. However, the mother says that the smaller twin has always been 'mothered' and protected by the larger and is very dependent on her.

Case 2. These twins are 3 years old. (twin I, birth weight, 2 lb. 12 oz., twin II, birth weight, 5 lb. 2 oz.). The mother has little control over either child. They both exhibit marked temper tantrums and are generally difficult to handle. However, the larger twin is much more independent. The smaller twin is said to be more excitable and highly strung and very dependent on the mother.

Case 3. These twins are $3 \frac{1}{2}$ years old (twin I, birth weight, 2 lb. $15 \mathrm{oz}$, twin II, birth weight, $4 \mathrm{lb} .2 \mathrm{oz}$.). The larger twin was friendly and cooperative and had always been much easier to handle. The smaller twin showed marked sleeping and feeding problems, was much more dependent on the mother, and was excessively timid and shy. She still indulged in temper tantrums 12 months after her brother had grown out of this phase.

Case 4. The twins are 7 years old (twin I, birth weight, 2 lb. $15 \mathrm{oz}$., twin II, birth weight, $3 \mathrm{lb}$. $6 \mathrm{oz}$.). The mother described the smaller twin as having always been highly strung, nervous and very excitable, in contrast to the larger twin who had never given any anxiety.

It is difficult to know whether the emotional immaturity of many of these children is a direct consequence of their low birth weight or whether it results from over-protection by the parents, and a transference of maternal anxiety to the child. It is possible that the deprivation of normal maternal care during the first few months of life may have some bearing on this problem. Bowlby (1953) suggests that the bad effects of separation from the mother may be evident from the age of a few weeks.

It seems likely that in at least one-third of these cases the emotional instability and immaturity may be as great a handicap to the child in later life as physical inferiority and mental slowness.

\section{Discussion}

A study of the growth and development of these 69 children with a very low birth weight suggests that the prognosis for the very small, premature 
infant is considerably worse than that reported by other workers. American writers suggest that at least $50 \%$ will be physically normal and rather more will be average in mentality. Corner (1952) reports on 70 surviving babies weighing less than $3 \mathrm{lb} .4 \mathrm{oz}$. at birth and states that $53(76 \%)$ were absolutely normal physically and mentally. However, in few of these investigations are details given of physical measurements, mental testing, or any indication as to what standards of normality are employed. It is possible that more detailed examination would have led to different conclusions.

When each case in this study was considered separately, it was found that at least two-thirds of the total were definitely handicapped as a result of their small birth weight. Moreover, if cases of retrolental fibroplasia are excluded, it was found that as many children in the 1-3-year-old group were severely handicapped as those in the school age group. It appears likely that as the survival rate in this low birth weight group improves an increasing number of damaged children will survive.

\section{Summary}

The results can be summarized as follows:

Physical Growth. The majority were considerably below average in both weight and height. Out of 64 children, only five had reached the expected weight for their age, and six out of 53 had reached the expected height. The retardation in weight was the most marked, the children being underweight for their height as well as generally small.

Mental Development. In a group of 38 pre-school children, only 14 were considered to have a development quotient of 90 or over. In the school age group of 21 children, three were considered to be of average intelligence.

Morbidity. Children in this low birth weight group appeared to be particularly susceptible to lower respiratory infections. In children of 3 years and under, the incidence was four times as high as that in a matched control group of maturely born children.

Physical Handicaps. Out of 31 children between the ages of 1 and 3 years, five were found to suffer from cerebral diplegia. One further case was found in the school-age group.

One-half of the children had a visual defect, and in one-third this could be considered a definite handicap.

Emotional Disorders. Behaviour problems were reported in two-thirds of the cases, and in one third the emotional disorder could be considered of quite a severe degree.

At least two-thirds of infants in the low birth weight group sustained physical, mental or emotional handicap in later infancy and childhood. This figure is considerably in excess of previous estimates and, moreover, about twice as many under-3-yearold children were severely handicapped as in those of school age. It is suggested that as the survival rate of very small premature infants improves an increasing proportion of damaged infants will survive.

I am indebted to the following, who supplied the data for the section on mental development in the school age group: Dr. W. N. Boog Watson, Chief Executive School Medical Officer, Edinburgh; Miss A. T. Paterson, Principal Educational Psychologist, Edinburgh; Dr. J. Riddell, Medical Officer of Health, Midlothian and Peeblesshire; Dr. C. B. Ross, County Medical Officer of Health, West Lothian; Dr. H. D. Wilson, County Medical Officer, East Lothian; Dr. A. Allan, Medical Officer of Health, Berwickshire; Mr. C. H. W. G. Anderson, Headmaster of the Royal Blind School, Edinburgh, and Dr. G. S. Dhillon, School Ophthalmologist, who provided ophthalmic reports on school age children. I would also like to thank Professor R. W. B. Ellis for his assistance and encouragement throughout.

This research programme has been supported by a grant from the Scottish Hospital Endowments Research Trust.

\section{REFERENCES}

Bowlby, J. (1953). Child Care and the Growth of Love, ed. M. Fry. London.

Corner, B. (1952). Bristol med.-chir. J., 69, 117.

Drillien, C. M. (1957). J. Obstet. Gynaec. Brit. Emp., 64, 161.

- and Richmond, F. (1956). Arch. Dis. Childh., 31, 390

Ellis, R. W. B. (1956). Disease in Infancy and Childhood, 2 nd ed. Edinburgh.

Hess, J. H. and Lundeen, E. C. (1949). The Premature Infant, 2nd ed. Philadelphia.

Howard, P. J. and Worrell, C. H. (1952). Pediatrics, 9, 577.

Knobloch, H., Rider, R., Harper, P. and Pasamanick, B. (1956). J. Amer. Med. Ass., 161, 581

Kunstadter, R. H. and Bartelme, P. F. (1934). In Hess, J. H. Mohr, G. J. and Bartelme, P. F. The Physical and Mental Growth of Prematurely Born Children, p. 221. Chicago. 